\title{
Papiloma escamoso del esófago: Hallazgo histopatológico infrecuente, a propósito de dos casos
}

\section{Squamous papilloma of the esophagus: Infrequent histopathological finding, a two-cases report}

Papiloma escamoso do esôfago: Um achado histopatológico raro, referindo-se a dois casos

\author{
Rubén Muñoz Cedeño (i) a, Gema Rodríguez Chica (i) b, Priscila Martínez Ballesteros (iD c \\ Viviana Paullán Sani id
}

a,c,d Servicio de Gastroenterología, Hospital de Especialidades Dr. Abel Gilbert Pontón, Universidad de Guayaquil, Guayaquil, Ecuador; b Unidad de Cuidados Intensivos Maternos, Hospital Universitario de Guayaquil, Guayaquil, Ecuador.

\section{Correspondencia a:}

Rubén Muñoz Cedeño, drubenmunoz@gmail.com

Recibido: 5 de septiembre, 2020 Aceptado: 9 de noviembre, 2020 Publicado: 30 de diciembre, 2020

\section{CASO CLÍNICO}

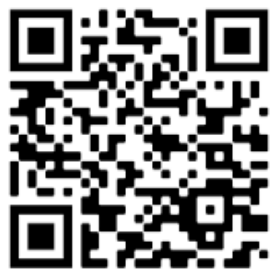

Escanea en tu dispositivo móvil o revisa este artículo en: https:// revistaclinicaguayaquil.org

\section{RESUMEN}

El papiloma escamoso del esófago es relativamente raro, tiene una prevalencia de 0.01 a $0.45 \%$. Generalmente es asintomático, de hallazgo incidental durante procedimientos endoscópicos. Se presenta más en hombres que mujeres, en una relación de 3:1, y su vía de transmisión es de manera directa. La infección oral por virus de papiloma humano se ha asociado a un subgrupo de carcinomas escamosos de la oro-faringe en pacientes con comportamientos sexuales de riesgo elevado. El diagnóstico temprano y oportuno es vital para el pronóstico. Se describen dos casos clínicos de pacientes femeninas, de edad entre 60 a 70 años, con antecedentes de cirrosis hepática, que acuden a la consulta de gastroenterología para realización de screening de várices esofágicas, durante el cual se evidenció, como hallazgos endoscópicos y corroborados con estudio anatomopatológico, la presencia de una lesión exofítica, con tallos fibrovasculares, correspondiente a la presentación clásica del virus del papiloma humano.

Palabras clave: papiloma escamo esofágico; virus del papiloma humano; papilomatosis esofágica

\begin{abstract}
Squamous papilloma of the esophagus is relatively rare, with a prevalence of 0.01 to $0.45 \%$. It is generally asymptomatic, it can be an incidental finding during endoscopic procedures. It occurs more often in men than women, in a 3:1 ratio, and its transmission route is direct. Oral human papillomavirus infection has been associated with a subgroup of squamous carcinomas of the oropharynx in patients with high-risk sexual behaviors. Early and timely diagnosis is vital for its prognosis. We present two female patients, between 60 and 70 years old, with past medical history of cirrhosis, who came to the Gastroenterology Service for an esophageal varices screening, during which an exophytic lesion with fibrovascular stems, corresponding to the classic presentation of the human papilloma virus was evidenced as endoscopic findings, and corroborated with a pathology study.
\end{abstract}

Key words: esophageal papilloma; human papilloma virus; esophageal papillomatosis

\section{RESUMO}

O papiloma escamoso do esôfago é relativamente raro, com prevalência de 0,01 a $0,45 \%$. Geralmente é assintomático, encontrado acidentalmente durante procedimentos endoscópicos. Ocorre mais em homens do que em mulheres, na proporção de 3: 1, e sua via de transmissão é direta. A infecção oral pelo 
papilomavírus humano foi associada a um subgrupo de carcinomas escamosos da orofaringe em pacientes com comportamentos sexuais de alto risco. O diagnóstico precoce e oportuno é vital para o prognóstico. Dois casos clínicos de pacientes do sexo feminino, com idade entre 60 a 70 anos, com história de cirrose hepática, que comparecem à consulta de gastroenterologia para rastreamento de varizes esofágicas, durante a qual foi evidenciado como achado endoscópico e corroborado com estudo anatomopatológico, a presença de lesão exofítica, com hastes fibrovasculares, correspondendo à apresentação clássica do papilomavírus humano.

Palavras-chave: papiloma esofágico escamoso; papilomavírus humano; papilomatose esofágica

\section{INTRODUCCIÓN}

El papiloma escamoso del esófago (PEE) es un tumor benigno del epitelio escamoso relativamente raro, con una prevalencia entre 0.01 a $0.45 \%$. Usualmente es asintomático, y se evidencia como hallazgo incidental durante un procedimiento endoscópico. Predomina más en hombres que en mujeres, con una relación de 3:1. En África Occidental existe la tasa de incidencia más baja y en China la más alta; en América Latina, México y Perú tienen bajo índice de mortalidad para carcinoma esofágico, mientras que Brasil, Argentina y Chile, reporta los niveles más altos (1). En el Ecuador no se encuentran datos reportados de papiloma esofágico.

En cuanto a la etiología existen 2 teorías: la primera, que se relaciona al tipo de reparación inflamatoria, como en las enfermedades de reflujo gastroesofágico crónico, esofagitis, el traumatismo menor, el impacto crónico de los alimentos, cirugía gastroesofágica previa, consumo de alcohol y cigarrillos; la segunda, asociada al virus del papiloma humano (VPH) que tiene importancia en la evolución a carcinoma escamoso en un 5 a $10 \%$, especialmente los tipos virales 16 y 18 (2). Su vía de transmisión es de manera directa; y la infección oral por VPH se ha asociado a un subgrupo de carcinomas escamosos del oro-faringe en pacientes con comportamientos sexuales de riesgo elevado (2).

El objetivo de este reporte de casos de papiloma escamoso del esófago es definir su diagnóstico, tratamiento y pronóstico.

\section{DESCRIPCIÓN DE LOS CASOS CLÍNICOS}

\section{CASO 1}

Paciente femenina de 61 años con antecedentes patológicos de hipertensión arterial controlada con losartán $50 \mathrm{mg}$, cirrosis hepática de etiología por virus de hepatitis B, con Child Pugh B (7 puntos), quien es valorada por la consulta externa de gastroenterología donde se programa para realizar screening de várices esofágicas, niega cualquier tipo de sintomatología digestiva.

Se realiza la video endoscopía alta donde se observa a los $28 \mathrm{~cm}$. de la arcada dentaria, en el extremo proximal del esófago, una lesión única, elevada y sésil, de color gris perlado, de bordes irregulares de aproximadamente $5 \mathrm{~mm}$ de diámetro (Figura 1). En el estómago se observa una pangastropatía erosiva en antro y cuerpo, y además, una duodenopatía eritematosa leve. Se toman biopsias para estudio anatomopatólogicos.

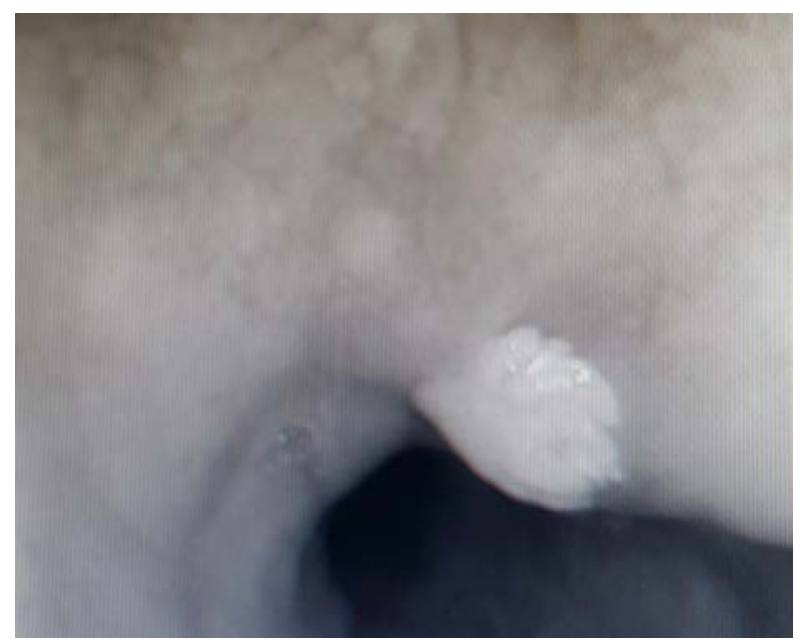

Figura 1. Imagen videoendoscópica, se observa lesión única, elevada y sésil de color gris perla.

La histopatología, confirmó la impresión diagnóstica endoscópica, informando una lesión exofítica con tallos fibrovasculares, recubierta por epitelio escamoso estratificado no queratinizado, con infiltrado inflamatorio leve, presencia de coilocitos (núcleo atípico rodeado de un anillo).

Se realizó un seguimiento endoscópico a los 6 meses con resultados de histopatología negativos.

\section{CASO 2}

Paciente femenina de 67 años con antecedentes patológicos de diabetes mellitus tipo 2 controlada con metformina $850 \mathrm{mg}$ cada día, hipertensión arterial controlada con losartán 100 mg, cirrosis hepática de etiología criptogénica, con Child Pugh A (5 puntos), niega síntomas digestivos o sangrado; es valorada por la consulta externa de gastroenterología donde se programa realizar screening de várices esofágicas. 
Se realiza la video endoscopía alta en la cual se observa, a los $25 \mathrm{~cm}$. de la arcada dentaria, en el extremo proximal del esófago, una lesión única, circular, polipoidea, vegetante y elevada, de aproximadamente $5 \mathrm{~mm}$ de diámetro y de color gris perlado, de bordes irregulares (Figura 2). Así también, en el estómago a nivel del antro se observa la mucosa con leve eritema, y el duodeno de aspecto normal. Se toman biopsias para el estudio anatomopatólogico.

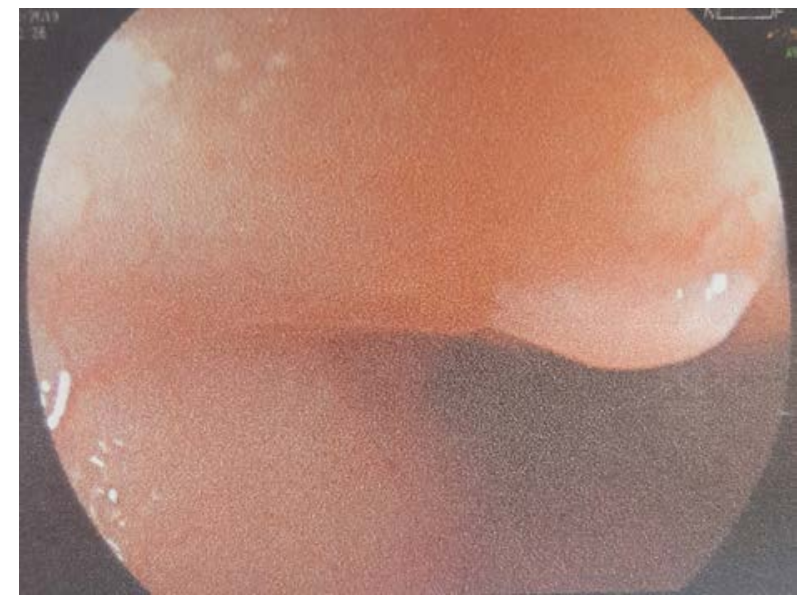

Figura 2. Imagen videoendoscópica, se evidencia lesión polipoidea vegetante, única, elevada y sésil de color gris perla.

La histopatología informó una lesión exofítica, con tallos fibrovasculares, recubierta por epitelio escamoso estratificado no queratinizado con infiltrado inflamatorio leve y presencia de coilocitos (células con núcleo atípico rodeado de un anillo). El seguimiento endoscópico a los 6 meses obtuvo un resultado de histopatología negativo.

\section{DISCUSIÓN}

El PEE es infrecuente, existen muy pocos reportes en el mundo y los casos diagnosticados son asintomáticos, probablemente son los más comunes en la actualidad. Los hallazgos endoscópicos son lesiones solitarias, ubicadas en el tercio medio y distal del esófago. Se manifiesta por pirosis, regurgitaciones, disfagia $y$ deterioro general, al no poder nutrirse adecuadamente; usualmente esta presentación clínica conlleva a realizar estudios endoscópicos donde se descubren las lesiones papilomatosas esofágicas (3). En los casos presentados, el hallazgo fue incidental por screening de varices esofágicas, sin manifestaciones clínicas como menciona la literatura.

El diagnóstico se realiza mediante endoscopía observándose una lesión única, circular, elevada, sésil de aspecto vegetante, pequeña y redondeada de superficie lisa o rugosa que habitualmente es menor de $1 \mathrm{~cm}$. El estudio histopatológico confirma el diagnóstico; al microscopio óptico se evidencia la presencia de coilocitos (células escamosas, generalmente en las capas intermedias, con una vacuola perinuclear bien definida y su núcleo hipercromático retraído), así también, la reacción en cadena de la polimerasa (PCR) que detecta el ADN viral para identificar el VPH tipo 16 o 18 , que son los genotipos más frecuentemente asociados con el carcinoma esofágico $(4,5)$.

El tratamiento para estas lesiones intraepiteliales escamosas incluye: criocirugía, láser, escisión electroquirúrgica con asa o cirugía convencional (6). El tratamiento que se realizó en los dos casos presentados fue la exéresis con pinza de biopsia por ser menores de $5 \mathrm{~mm}$; no se evidenció recidiva en el sitio de la resección hasta la actualidad.

El PEE es una neoplasia histológicamente benigna $y$, aunque se realice una exéresis correcta, la enfermedad recidiva con frecuencia en un $4 \%$ de los pacientes. Se requiere revisiones periódicas hasta conocer el patrón evolutivo en cada paciente (3). No existe actualmente un consenso sobre el manejo o seguimiento de la papilomatosis esofágica. En los dos casos se decidió, con el equipo multidisciplinario, realizar controles endoscópicos con biopsias seriadas a los 6 meses, en los cuales los resultados de las biopsias obtenidas fueron negativas para PEE.

El pronóstico del PEE asociado con cáncer esofágico es malo a corto y mediano plazo por la localización del tumor, la extensión, la estructuras vecinas importantes y vitales; aunque no se demuestre metástasis al momento del diagnóstico (7). Es así que se sugiere que toda lesión elevada, con las características previamente descritas, sean biopsiadas para descartar una neoplasia histológicamente benigna, ya que el diagnóstico temprano es esencial para mejorar el pronóstico de esta enfermedad y mejorar la calidad de vida de los pacientes.

\section{REFERENCIAS BIBLIOGRÁFICAS}

1. Herrera-Goepfert R, Lizano M, Akiba S, CarrilloGarcía A, Becker-D’Acosta M. Human papilloma virus and esophageal carcinoma in a LatinAmerican region. World J Gastroenterol. 2009; 15(25):3142-3147.

2. Pineda Oliva OJ, Valencia Romero A, Valdivia Balbuena M, Díaz Oyola M, Cuevas Osorio V, Soto Pérez JC, et al. Papiloma escamoso del esófago: reporte de 31 casos en un hospital de tercer nivel. Endoscopia. 2015; 27(1):31-35. 
3. Bohn OL, Navarro L, Saldivar J, Sanchez-Sosa S. Identification of human papillomavirus in esophageal squamous papillomas. World J Gastroenterol. 2008; 14(46):7107-7111.

4. Barbaglia $Y$, Jiménez $F$, Tedeschi $F$, Zalazar $F$. Papiloma esofágico: Descripción de un caso, identificación molecular del virus del papiloma humano y revisión de la literatura. Acta Gastroenterológica Latinoamericana. 2013; 43(3):231-234.

5. Fernández Sotolongo J, Astencio Rodríguez G, Suárez Romero M, Díaz Elías JO. Papilomatosis esofágica. Presentación de un caso. Revista Archivos del Hospital Universitario "General Calixto García". 2017; 5(2):293-301.
6. Roesch-Dietlen F, Cano-Contreras AD, SánchezMaza YJ, Espinosa-González JM, Vázquez-Prieto M, Valdez de la O EJ, et al. Frecuencia de infección por virus del papiloma humano en pacientes con cáncer del aparato digestivo. Revista de Gastroenterología de Mexicana. 2018; 83(3):253258.

7. Serrá Valdés MA, Fojo Mallo AW, González Valera N, Cardosa Samón M, García Tassé M, Aleaga Hernández YY. Infección por papilomavirus humano y cáncer esofágico: reporte de caso. Medwave. 2012; 12(9):e5531.

\section{ACERCA DE LOS AUTORES}

1. Rubén Muñoz Cedeño: Médico Posgradista de Gastroenterología, Hospital de Especialidades Dr. Abel Gilbert Pontón, Universidad de Guayaquil, Ecuador.

ORCID: 0000-0003-0146-2488

2. Gema Rodríguez Chica: Magister en Seguridad y Salud Ocupacional, Universidad Espíritu Santo. Médico Residente de la Unidad de Cuidados Intensivos Maternos, Hospital Universitario, Universidad de Guayaquil, Guayaquil, Ecuador. ORCID: 0000-0002-7772-1186

3. Priscila Martínez Ballesteros: Médico especialista en Gastroenterología, Universidad de La Habana, Cuba; Coordinadora del Posgrado de Gastroenterología, Universidad de Guayaquil; Formación en Ecoendoscopía en La Plata, Argentina. Hospital de Especialidades Dr. Abel Gilbert Pontón, Guayaquil, Ecuador.

\section{ORCID: 0000-0003-4148-0859}

4. Viviana Paullán Sani: Médico especialista en Gastroenterología, Universidad de La Habana, Cuba; Líder del servicio de Gastroenterología del Hospital de Especialidades Dr. Abel Gilbert Pontón; Tutora del Posgrado de Gastroenterología, Universidad de Guayaquil, Guayaquil, Ecuador.

ORCID: 0000-0001-9836-4854 